\title{
Assessment of the veterinary cost recovery scheme in the Amhara region, Ethiopia
}

\author{
Solomon Woldemariam ${ }^{1 *}$, Ali Abdi ${ }^{1}$, Wondwosen Asfaw ${ }^{2}$ and Tesfaye Haile ${ }^{2}$ \\ ${ }^{1 *}$ HABCON Consult, Addis Ababa, Ethiopia \\ ${ }^{2}$ AGP-Livestock Market Development Project, Addis Ababa, Ethiopia \\ *corresponding author email: solomonwolde04@yahoo.com
}

\begin{abstract}
This study was conducted in November, 2015 in selected Woredas of Amhara region with the aim of assessing the impact of veterinary cost recovery on efficiency of public private livestock services and to share the experience of the region with other regional states. Structured questionnaire and a field survey with focus group discussion were applied on a total of 475 randomly selected households. Animal health service in the Amhara region is clearly dominated by the public sector. Private-sector involvement was prominent only in the veterinary drug sales and treatment services. Seventy five percent of livestock owners responded that they received veterinary services from their residence within $1 \mathrm{~km}$ radius. The results indicated that only $18 \%$ of respondents were satisfied by clinical examination provided by public sector. There was wide disparity in the effectiveness of delivery of animal health services between public and private sectors in the study Woredas. Majority of farmers were not been satisfied with the services provided by private sector. The supply of drugs is increasing especially after implementation of veterinary cost recovery scheme but with the limited ranges. Most respondents had positive views regarding availability of veterinary drugs (62.2\%) and vaccines (78.1\%). Many livestock owners believed that illegal veterinary drug sales have decreased after implementation of veterinary cost recovery scheme (VCRS). The fact that payment for veterinary services has already been adopted by livestock owners in the study Woredas could be considered as a good opportunity to start a full cost recovery scheme as well as pave the way for initiating veterinary privatization in some pilot Woredas.
\end{abstract}

Keywords: Amhara Region; Drug sales; Private; Public; Revolving fund; Veterinary cost recovery scheme 


\section{Introduction}

Ethiopia is one of the African countries with the highest livestock population. However, the country is not benefiting from this huge resource due to various reasons. Generally, livestock are of economically and socially important both at the household and national levels, and have in the past provided significant export earnings. Livestock contribute 15 to $17 \%$ of GDP and 35 to $49 \%$ of agricultural GDP, and 37 to $87 \%$ of the household income (EATA, 2013).

Livestock play an enormous role in reducing poverty in the livelihood of the majority of the rural and peri-urban poor. They contribute food and nutritional security; they generate income and are an important storage of wealth, transport and sources of power, and their manure maintains soil fertility (Abebe, 2013). While national data are not available, data from individual contents lead to an estimate of several billion Ethiopian Birr (ETB) in losses in animal products caused by diseases annually. For example, losses because of mortality are estimated between 16 to 20 billion ETB per year. Existing data indicate that the annual production losses (growth, fertility, and work output) due to morbidity could reach 30-50\% (Asfaw, 2013).

Full livestock productivity is highly dependent on the availability and provision of high quality and dependable animal health services. However, poor animal health is a major constraint to increasing livestock production in the country. Even though government veterinary institutions traditionally provide basic animal health services, they generally encounter financial shortfalls limiting their ability to deliver sustainable animal health services.

In keeping with the principle of public private partnership in the delivery of veterinary services, the Amhara National Regional State (ANRS) introduced cost recovery scheme to improve the performance of public animal health service delivery, the first of its kind. The program was officially initiated in April 2013 after the regional council endorsed one million ETB to allocate to each administrative Woreda in the form of revolving fund (RF) for purchasing of veterinary drugs and equipment. Since then, there have not been any assessments conducted on the effect of veterinary cost recovery on the delivery of public private services in the region. This study, therefore, was conducted in this particular region with the aim of assessing the impact of veterinary 
cost recovery scheme on the efficiency of public private livestock services and shares the experience of the region to other regional states.

\section{Materials and methods}

General background on geographical location and livestock potential of Amhara region

The ANRS is located in the North-western part of Ethiopia. Geographically, it is situated between latitude $9^{\circ}-13^{\circ} 45^{\prime} \mathrm{N}$ and longitude $36^{\circ}-40^{\circ} 30^{\prime} \mathrm{E}$. The total area of the region is estimated at $152,559 \mathrm{~km}^{2}$ which is about one-sixth of country's total area (BoFED, 2006). The region holds a total of 30, 037,577 livestock ( $26 \%$ of the national population) that comprises 13,371,486 cattle, 8679,879 sheep, 5,176,309 goats, 2,758,431 equines and 51,472 camels (CSA, 2012). Poor animal health is a major constraint to increasing livestock production in the region. Full livestock productivity is highly dependent on the availability of regular provision of high-quality animal health services.

The information received from Amhara Livestock Resource Development Promotion Agency (2015) indicated that there are 131 Woreda level veterinary clinics, 1956 kebele/village level animal health posts (AHPs), 2 animal disease diagnostic and investigation laboratories, 4 cold chain vaccine stores (not yet functional) and 7 abattoirs (3 export and 4 municipal abattoirs) under the public service sector. The private sector runs 277 clinics and 455 drug shops in the region. The construction of public animal health posts at Kebele level is progressing rapidly. During the study period, 183 public animal health posts were under construction and raising the total number to 2139 in the region. As far as man power is concerned, there are 302 veterinarians (DVM, MVSc) and 3001 veterinary paraprofessionals within public services and 133 veterinarians (DVM) and 699 veterinary paraprofessionals in the private sector.

\section{Selection of the study area and sample size determination}

A combination of multistage and purposive sampling methods was used to select the study areas. In the $1^{\text {st }}$ stage administrative zones of the region were divided under two strata to represent productive and food insecure zones. In the $2^{\text {nd }}$ stage target administrative zones were chosen on the basis of their performance of veterinary cost recovery scheme. In the $3^{\text {rd }}$ stage, target Woredas from each zone were selected purposively to represent those which were ac- 
tively involved in the cost recovery scheme and those which showed relatively low performance.

Hence, the study was conducted in eight words namely Deben and Awabel of East Gojjam Zone, Bahir Dar Zuria and Gonji of West Gojjam Zone, Fogera and Farta of South Gondar Zone, Meket and Gubalafto of North Wollo Zone of Amhara region. Generally, most part of the study Woredas are midland and are favorable for livestock raising with similar tropical/sub-tropical condition. There are two distinct seasons, the rainy season from June to September and dry season from October to May. In some Woredas (Meket and Gubalafto) there is additional short rainy season between the month of March and May.

In the $4^{\text {th }}$ stage a list of peasant associations (PAs) within Woreda was made from documents obtained from the Woreda's Agricultural Office and selected three PAs (two rural kebeles and one urban/peri-urban) based on accessibility. Then a list of households as a sampling frame was taken from office of Kebele Administrative Council and by using simple random sampling technique 50 households were selected from each PA to participate in the study.

The required sample size for the quantitative data collection was calculated using a formula given by Yamane, (1967) which assumes 95\% confidence level and the maximum variance $(p=0.05)$. Therefore, a sample size of 400 was considered for this study. In order to accommodate non-response rate and defective questionnaires we added $20 \%$ to the calculated sample size and increased the total sample size to 480 .

$\mathrm{n}=\mathrm{N} / 1+\mathrm{N}(\mathrm{e}) 2$

Where - $\mathbf{n}$ is the sample size, Ndenotes the population size and e specifies the desired level of precision, where $e=1-$ precision.

\section{Data collection}

Both quantitative and qualitative primary data were collected through closed and open-ended questionnaire and interview sessions with the Public and Private Veterinary Practitioners. Target groups for questionnaire survey were livestock producers (farmers, households), private and public veterinary clinics, public animal health posts and private veterinary drug shops. Secondary data were obtained from monthly, quarterly and annual reports of the Amhara 
Livestock Resource Development Promotion Agency. Other sources of information were journals, books, internet, publications and government depository.

The level of satisfaction of beneficiaries in the context of accessibility, affordability, sustainability, quality and efficiency of veterinary public or private veterinary service delivery was measured by interview. In addition to this, attempts were made to collect the financial records of the Woreda veterinary clinics and AHPs and the bank statements of the Woreda Finance and Economic Development Offices. Focus group discussions (FGD) were also conducted at Woreda and kebele level to get the opinion of veterinary service providers and beneficiaries, and other relevant actors on veterinary cost recovery scheme.

\section{Data analysis}

Collected information was analyzed by the use of the Statistical Package for Social Sciences (SPSS). Qualitative information obtained from key informants was analyzed using content analysis. Descriptive analysis was performed by computing descriptive statistics including frequencies, percentages and minimum and maximum values of ordinal variables.

\section{Results}

\section{Revolving fund allocation and utilization}

According to data collected from Regional Livestock Resource Development Promotion Agency, 148 Woredas have allocated a total of 101 million ETBas revolving fund (RF) for purchase of veterinary drugs and equipment. However, on average the available fund allocated to each Woreda was estimated to reach $682,432 \mathrm{ETB}$. At region, the amount of money used for RF scheme increased from 8 million ETB to more than 110 million ETB over the period of 2010-2015.

\section{Demographics of respondents}

More than $75 \%$ (rural $62.8 \%$ and peri-urban $12.3 \%$ ) of the total respondents were livestock producers, private farms accounted for $5.2 \%$, private veterinary drug shops and clinics (8.6\%) and Woreda level veterinary clinic and AHP (11.1\%)(Table 1). In terms of sex, about $91 \%$ of the $\mathrm{HH}$ respondents were male, while female headed $\mathrm{HH}$ account $9 \%$ only. With regard to levels of education, 
around $25 \%$ of $\mathrm{HH}$ respondents were illiterate, some $30 \%$ have completed adult education and the rest had attended primary and secondary education.

Table 1. Number of respondents by Woreda and type of veterinary service providers

\begin{tabular}{|c|c|c|c|c|c|c|c|c|}
\hline \multirow{2}{*}{$\begin{array}{l}\text { Woreda } \\
\text { Admin. }\end{array}$} & \multicolumn{2}{|c|}{ Farm Household } & \multirow{2}{*}{$\begin{array}{l}\text { Private } \\
\text { farm }\end{array}$} & \multicolumn{2}{|l|}{ Public } & \multicolumn{2}{|l|}{ Private } & \multirow[t]{2}{*}{ Total } \\
\hline & Rural & $\begin{array}{l}\text { Peri- } \\
\text { urban }\end{array}$ & & $\begin{array}{l}\text { Vet } \\
\text { clinic }\end{array}$ & AHP & $\begin{array}{l}\text { Vet. } \\
\text { clinic }\end{array}$ & $\begin{array}{l}\text { Drug } \\
\text { shop }\end{array}$ & \\
\hline Awabel & 50 & 10 & 5 & 8 & 1 & 2 & 5 & 81 \\
\hline $\begin{array}{l}\text { Bahir Dar } \\
\text { Zuria }\end{array}$ & 22 & 10 & 6 & 6 & 1 & 1 & 1 & 47 \\
\hline $\begin{array}{l}\text { Bahir Dar } \\
\text { City }\end{array}$ & 25 & - & 2 & - & - & 1 & 9 & 37 \\
\hline Dejen & 50 & 10 & 4 & 7 & 1 & 2 & 1 & 75 \\
\hline GonjiKolela & 50 & 10 & - & 5 & - & 2 & 2 & 69 \\
\hline Farta & 50 & 10 & 8 & 10 & 1 & 2 & 8 & 89 \\
\hline Fogera & 50 & 10 & 2 & 10 & 1 & 2 & 10 & 85 \\
\hline Gubalafto & 50 & 10 & 5 & 8 & - & 2 & - & 75 \\
\hline Meket & 50 & 10 & 1 & 10 & 1 & 2 & 2 & 74 \\
\hline Total(\%) & $397(62.8)$ & $78(12.3)$ & $33(5.2)$ & $64(10.1)$ & $6(1)$ & $16(2.5)$ & $38(6.1)$ & $632(100)$ \\
\hline
\end{tabular}

\section{Animal health services}

Of the total of 182 veterinary centers involved in the study, 144 and 38 were government veterinary clinics/AHPs and private veterinary centers, respectively (Table 2). Seventy percent of farmers responded that they received animal health services from public veterinary centers (clinics and/or AHPs). With regard to distance of veterinary centers, majority (75\%) of livestock owners responded that they received veterinary services from their residence within $1 \mathrm{~km}$ radius.

Table 2. Numbers of veterinaryfacilities by type in the study Woredas (2015)

\begin{tabular}{lccc}
\hline S Sector & Clinics and/or AHPs (\%) & Drug shops (\%) & Total (\%) \\
\hline Public & $144(78 \%)$ & $0(0 \%)$ & $144(78 \%)$ \\
Private & $21(12 \%)$ & $17(10 \%)$ & $38(22 \%)$ \\
Total & $165(90 \%)$ & $17(10 \%)$ & $182(100 \%)$ \\
\hline \multicolumn{2}{l}{ Source: Amhara Region Livestock Resource Development and Promotion Agency (2015) }
\end{tabular}


Attempts were made to rank veterinary services in relation to farmers' choices. Thus, majority (96\%) of farmers rank public as first choice followed by private animal health clinic and then private drug shop (Table 3).

Table 3. Ranking public and privateanimal health services

\begin{tabular}{lcccccc}
\hline \multirow{2}{*}{ Ranking } & \multicolumn{2}{c}{ Public } & \multicolumn{3}{c}{ Private } & \multicolumn{2}{c}{ Private drug shop } \\
\cline { 2 - 7 } & Frequency & $\%$ & Frequency & $\%$ & Frequency & $\%$ \\
\hline First & 453 & 96.0 & 12 & 2.5 & 75 & 15.9 \\
Second & 11 & 2.3 & 174 & 36.9 & 2 & 0.4 \\
Third & 2 & 0.4 & 32 & 6.8 & 150 & 31.8 \\
\hline
\end{tabular}

\section{Revenue collection}

The computed annual average service revenue for Awabel, Dejen, Fogera and Meket was $8972.00 \mathrm{ETB}, 7361.4 \mathrm{ETB}, 5010.2 \mathrm{ETB}$ and 68.7ETB, respectively. It gives a maximum of 8972.0ETB for Awabel and a minimum of 68.9 ETB for Meket Woreda. The service revenue from total sales for the sampled Woredas ranged from 5\% (Meket Woreda) to 22\% (Fogera Woreda). With regard to gross revenue, $85 \%$ and $78 \%$ were generated from drug sales for Awabel and Fogera Woreda, respectively. In Meket Woreda, 95\% of revenue was generated from sales of drugs.

\section{Level of satisfaction of farmers to animal health services}

As shown in Table 4, $10.6 \%, 18.0 \%, 20.6 \%$, and $21.0 \%$ of respondents scored satisfactory for treatment, clinical examination, vaccination and other services provided by public sector/AHP/, respectively. Almost 56.0\%, 26.0\%, 11.3\% and $6.1 \%$ of farmers scored satisfactory, poor, good and very good for the services they obtained from private sector, respectively. 
Woldemariam et al.,

Table 4. Level of satisfaction of farmers with services delivered with public animal health posts (AHPs)

\begin{tabular}{lcccccc}
\hline $\begin{array}{l}\text { Animal } \\
\text { health } \\
\text { services }\end{array}$ & $\begin{array}{c}\text { Very good } \\
\text { (\%) }\end{array}$ & Good (\%) & Satisfactory (\%) & $\begin{array}{c}\text { Poor } \\
\text { (\%) }\end{array}$ & $\begin{array}{c}\text { Missing } \\
\text { (\%) }\end{array}$ & $\begin{array}{c}\text { Total } \\
\text { (\%) }\end{array}$ \\
\hline $\begin{array}{l}\text { Clinical } \\
\text { examination }\end{array}$ & $6(1.3)$ & $43(9.1)$ & $85(18.0)$ & $75(15.9)$ & 263 & 472 \\
Vaccination & $171(36.2)$ & $153(32.4)$ & $97(20.6)$ & $24(5.1)$ & $27(5.7)$ & $\begin{array}{c}472 \\
(100)\end{array}$ \\
Treatment & $204(43.2)$ & $186(39.4)$ & $50(10.6)$ & $10(2.1)$ & $22(4.7)$ & $\begin{array}{c}472 \\
(100)\end{array}$ \\
$\begin{array}{l}\text { Other } \\
\text { services }\end{array}$ & $159(33.7)$ & $134(28.4)$ & $99(21.0)$ & $47(10.0)$ & $33(7.0)$ & $\begin{array}{c}472 \\
(100)\end{array}$ \\
\hline
\end{tabular}

Most respondents (62.2\%) had positive views regarding availability of veterinary drugs in public veterinary services. The result showed that $78.1 \%$ of respondents are satisfied with the accessibility of vaccines in the area. Moreover, available data indicated that the number of animals treated in the region was increasing after the implementation of veterinary cost recovery scheme (20132015) compared to previous years. The same is true for vaccination. Table 5 shows total number of animals treated and vaccinated between the years 2011 and 2015 in the Amhara region.

Table 5. Numbers of animal treated and vaccinated (inmillion) (2011-2015)

\begin{tabular}{lccc}
\hline Year & Vaccinated & Treated & Total \\
\hline 2011 & 10.0 & 15.0 & 25.0 \\
2012 & 9.4 & 11.5 & 20.8 \\
2013 & 11.2 & 17.6 & 28.8 \\
2014 & 20.8 & 19.0 & 39.8 \\
2015 & 23.3 & 23.4 & 46.70 \\
\hline
\end{tabular}

Source: Amhara Region Livestock Resource Development and Promotion Agency (2015)

Survey results indicate that more than $63 \%$ of the private practitioners replied that obtaining license is not a challenge. According to information obtained from the regional Livestock Resource Development and Promotion Agency (LRDPA), the number of private drug shops in the region has increased by $50 \%$ and that of private clinics tripled over the past three years. 


\section{Discussion}

This survey shows that each sample Woreda allocated one million ETB as a RF except Gonji Kollela which had about 306,000 ETB to run the VCRS. This measure has considerably reduced the budgetary burden which has not been adequately funded for veterinary inputs purchase by LRDPA in previous years.

Majority $(70 \%, \mathrm{n}=332)$ of farmers received animal health services from government veterinary centers a finding that agrees with works of Moorhouse and Tolossa (1998). With regard to accessibility, it was observed that most private veterinary centers (clinics and drug shops) were established in major cities and towns. Many farmers $(75 \%, \mathrm{n}=356)$ received veterinary services from their residence within $1 \mathrm{~km}$ radius. This shows that the construction of public animal health posts at kebele level is progressing rapidly and so that clinical service is provided to livestock owners at nearby public veterinary centers.

Majority (96\%) of farmers ranked public veterinary service as first priority followed by private animal health clinic and then private drug shop as their overall preference for veterinary service delivery. Similarly, a study on animal health service delivery in North Gondar showed that $58.5 \%$ of respondents preferred the government service, $21.4 \%$ liked both services equally and $20.3 \%$ preferred the private service (Kebede et al., 2014).

Respondents during the Focus Group Discussions (FGD) clearly mentioned that accessibility, affordability, quality and sustainability of veterinary services are factors for preference. The study revealed that $84 \%(n=399)$ of farmers can afford to pay service and drug sale charges to public veterinary center in comparison with charges to pay to private centers. However, $87 \%(n=29)$ of livestock producers in Dejen Woreda considered the prices charged to be acceptable in private clinics. It was also observed that the issue of affordability was challenging for government to provide rapid and effective clinical veterinary care in drought affected Woreda such as Gubalafto.

Before the introduction of VCRS, clinical services that were provided by government clinics were predominantly subsidized or provided free in the region. Users were required to cover only the cost of drugs. Under the new arrangement, livestock owners are required to pay for the services they get and a margin of $15 \%$ on drugs. The result showed that most of the animal health service providers at Kebele level did not have veterinary drug dispensers who provide 
both professional services and cash collection. This has created a burden on the animal health professionals and affected the speed of service provision. It also creates a room for malpractices.

In most cases the service fee collected was highly understated as compared to physical performance or services provided (clinical examination, close castration). In addition to this, the average service revenue per clinic in the Meket Woreda was below one ETB per day. Major reasons for little service revenue include lack of commitment to collect payment for clinical examination as per the VCRS guideline, lack of drug dispenser, poor monitoring and evaluation system, absence of timely audit and lack of training on revenue collection, recording and reporting.

The public involvement in provision of clinical and laboratory examination services at Kebele level was poor. This might be associated with lack of adequate clinical and laboratory equipment. Most veterinary workers assigned in AHPs have lack of training and their efficiency decreased over time. With regard to level of satisfaction, majority of farmers had not been satisfied with the services provided by private sector. In most FGDs many farmers believed that the private drug shops and clinics have no genuine products and also doubtful about the shelf life of drugs sold by these centers. This clearly demonstrated that there is lack of awareness and misconceptions regarding veterinary privatization on the part of livestock keepers.

At initial stage of the program,it was challenged that most beneficiaries had not fully understood as to why they need to pay for services. It was obvious that farmers were accustomed to government subsidization and were reluctant to pay for veterinary services. This, in turn, led to less revenue for the RF, insufficient for the purchase of large quantity of inputs. After farmers' participation and full understanding of the program, sufficient amounts of money were collected that enabled bulk purchases. Even though there was no budgetary constraint for purchase of drugs in government veterinary clinics, there was problem of administering the $\mathrm{RF}$ such as absences of purchase plan to ensure steady supply of drugs in all sample Woredas. As a result of this, considerable number of veterinary clinics had encountered inadequate supply of veterinary drugs besides getting diversified veterinary products, which is also pronounced throughout the region. 
The introduction of the veterinary cost recovery scheme has minimized the price gap between public and private AHS providers. The unfair competition due to subsidized or free service has reduced. However there is still difference in price as well as service charges between the two sectors and this could change when full cost recovery scheme is introduced.

Analysis of result indicates that $26.3 \%(\mathrm{n}=10)$ of the private practitioners were discouraged by VCRS. The reasons given by them include moon-lighting public sector staff and failure to enforce rules, poor inspection and control system on public veterinary clinics and AHPs, poor linkage between public and private sectors, unfair government veterinary drug cost. In general, the public sector has not been very successful in regulating the malpractices. Supplementary income of public sector staffs through moon-lighting was the major problem in the implementation of VCRS. The research team proofed that there was wide variation for instance between numbers of castrated animals reported and amount of money collected from the service provided. Evidence suggests moon-lighting public sector staff, some $25 \%$ of public animal health staff admitted to supplementing their salary through private out-of-hours work, this is surely the 'tip of the iceberg' (Moorhouse, 2013).

\section{Conclusion}

This study revealed that the supply of veterinary products particularly drugs to Woredas is increasing after implementation of veterinary cost recovery scheme. However, there are very limited range and quality of veterinary products that cannot improve the quality of veterinary services in the region. Payments for veterinary services have already been adopted by livestock owners in the study Woredas which is a good opportunity to start a full cost recovery scheme and pave the way for initiating veterinary privatization in some pilot Woredas. The accessibility of veterinary drugs in public sectors has reduced and closed down the illegal trading of veterinary products advertised by personnel with limited technical competence. In other aspect, lack of inspection and control of moon-lighting by public animal health staffs discourage many legal veterinarians and para-veterinary professionals. It is very important to establish periodic monitoring and evaluation system of veterinary cost recovery scheme in the region. The VCRS guidelines and/or directives should be revised in order to solve matters which create confusion. 


\section{Acknowledgements}

The authors would like to thank the SNV-Agricultural Growth Program-Livestock Market Development Project for funding this study.

\section{Conflict of interest}

The authors declare that there is no conflict of interest.

\section{References}

Abebe, G., 2013. Animal Health Professional in Ethiopia.In: Proceedings of the National Symposium on Enhancing Economic Growth Through Livestock Development Ethiopia. University of Gondar Faculty of Veterinary Medicine, 7-8 June 2013, Gondar, Ethiopia.

Amhara Region Livestock Resource Development and Promotion Agency, 2015.Annual Report.

Asfaw, W., 2013. Animal Health and Its Multidimensional Contribution.In: Proceedings of the National Symposium on Enhancing Economic Growth Through Livestock Development Ethiopia. University of Gondar Faculty of Veterinary Medicine, 7-8 June 2013, Gondar, Ethiopia.

BoFED, 2006. Bureau of Finance and Economic Development. Development indicators of Amhara Region. July, 2006. Bahir Dar, Ethiopia.

CSA, 2012. Agricultural Sample Survey Volume II, Report on livestock and livestock characteristics, Central Statistic Authority, Addis Ababa, Ethiopia. Pp. 35-49.

EATA, 2013. Ethiopian Agricultural Transformation Agency. Livestock, availability at http://www.ata.gov.et/programs/value-chain-programs/livestock/ [accessed June 13, 2015]

Kebede, H., Melaku, A. and Kebede, E., 2014. Constraints in animal health service delivery and sustainable improvement alternatives in North Gondar, Ethiopia. Onderstepoort J. Vet. Res. 81(1), Art.\#713, 10 pages.http://dx.doi.org/10.4102/ojvr. v81i1.713

Moorhouse, P. 2013. Proposed Road Map for Privatization of Veterinary Services in Ethiopia. In: Proceedings of the $27^{\text {th }}$ Annual Conference of the Ethiopian Veterinary Association, 06-07 September 2013, Addis Ababa, Ethiopia.

Moorhouse, P. and Tolossa, A., 1998. PARC Ethiopia: Consultancy report on cost recovery.

Yamane, T.1967. Statistics: An Introductory Analysis, 2nd edition, Network: Harper and Row. 